\title{
STUDY OF FACTORS INFLUENCING THE NONCLOSURE OF BRONCHOPLEURAL FISTULA IN PATIENTS WITH SPONTANEOUS PNEUMOTHORAX
}

\author{
M. Ejaj Ahmed ${ }^{1}$, G. Aruna², Neethi Chandra ${ }^{3}$ \\ ${ }_{1}^{1}$ Post Graduate, Department of Pulmonary Medicine, S. V. Medical College, S. V. R. R. G. G. H. \\ ${ }^{2}$ Associate Professor, Department of Pulmonary Medicine, S. V. Medical College. \\ ${ }^{3}$ Assistant Professor, Department of Pulmonary Medicine, S. V. Medical College, S. V. R. R. G. G. H.
}

\begin{abstract}
A pneumothorax is an abnormal collection of air or gas in the pleural space. Pneumothoraces are essentially of two types, spontaneous and tramautic pneumothoraces, based on whether the lung is diseased or not. Spontaneous pneumothoraces are further of two types- primary and secondary spontaneous pneumothoraces. A subcategory of traumatic pneumothorax is iatrogenic pneumothorax. Hydro-pneumothorax, pyo-pneumothorax and hemo-pneumothorax result from collection of clear fluid, pus and blood respectively in the pleural cavity. A bronchopleural fistula is a communication between the pleural space and the lung.
\end{abstract}

\section{MATERIAL AND METHODS}

A prospective study of 54 cases of spontaneous pneumothorax with bronchopleural fistula, which were admitted in Department of Pulmonary Medicine, SVRRGGH, Tirupathi, over a period of 1 year from July 2014 to July 2015 was undertaken. Patients with pneumothorax were identified by clinical and radiological examination, where it was necessary for CT chest to be performed. Depending on the chest x ray and CT chest findings, the patients were subjected to tube thoracotomy. Patients who had persistent bronchopleural fistula after 15 days had to be referred to the CT surgeon for decortication or pleurectomy. For all those whose bronchopleural fistula closed by itself, the intercostal tube was removed at the earliest. After completion of the study, the findings and results were analysed and compared with those of the previous studies.

\section{RESULTS}

In the study period, out of 120 pneumothorax patients 54 patients with bronchopleural fistula were diagnosed. In 34 of the 54 patients, that is in $63 \%$ the bronchopleural fistula healed spontaneously in 2 weeks' time. In 16 of the patients even after 15 days of intercostal tube drainage, the bronchopleural fistula did not heal and they had to be referred to the cardiothoracic surgeon for decortication/pleurectomy; 46 of the 54(85.2\%) were males and 8(14.8\%) were females; 45 patients (83\%) had TB pneumothorax; out of this 2 were MDR TB patients; 9 patients out of 54(17\%) had non-TB pneumothorax, in which 2 were carcinoma lung; $7(13 \%)$ out of 54 patients, all men had diabetes, 2 of the 54 were HIV positive. There were 4 deaths, all of them due to aspiration pneumonia.

\section{CONCLUSIONS}

Men with TB pneumothorax, hydro- and pyo-pneumothorax seem to have delayed and non-closure of the bronchopleural fistula. Carcinoma lung seems to be associated with non-closure of the bronchopleural fistula more frequently. Diabetes and HIV do not influence the closure of the bronchopleural fistula according to our study.

\section{KEYWORDS}

Pneumothorax, Bronchopleural Fistula, TB, CA Lung.

HOW TO CITE THIS ARTICLE: M. Ejaj Ahmed, G. Aruna, Neethi Chandra. "Study of Factors Influencing the Nonclosure of Bronchopleural Fistula in Patients with Spontaneous Pneumothorax." Journal of Evolution of Medical and Dental Sciences 2015; Vol. 4, Issue 96, November 30; Page: 16144-16146, DOI: 10.14260/jemds/2015/2367

INTRODUCTION: A pneumothorax is an abnormal collection of air or gas in the pleural space. Pneumothoraces are essentially of two types, spontaneous and tramautic pneumothoraces, based on whether the lung is diseased or not. Spontaneous pneumothoraces which occur without antecedent trauma or other obvious cause and tramautic pneumothoraces which occur from direct or indirect trauma to the chest. Spontaneous pneumothoraces are of two types, primary and secondary spontaneous pneumothoraces.

Financial or Other, Competing Interest: None.

Submission 19-10-2015, Peer Review 20-10-2015,

Acceptance 20-11-2015, Published 27-11-2015.

Corresponding Author:

Dr. M. Ejaj Ahmed,

H. No. 9-68,

Amaravathi Nagar-517502

Tirupathi.

E-mail: ejaj0061@gmail.com

DOI:10.14260/jemds/2015/2367
Primary spontaneous pneumothoraces occurs in otherwise healthy individuals. The general consensus is that primary spontaneous pneumothorax results from rupture of subpleural emphysematous blebs that are usually located in the apices of the lung.1,2 Secondary spontaneous pneumothoraces occur as a complication of underlying lung disease, most commonly Chronic Obstructive Pulmonary Disease (COPD). A subcategory of traumatic pneumothorax is iatrogenic pneumothorax, which occurs as an intended or inadvertent consequence of a diagnostic or therapeutic maneuver.

The most common cause of iatrogenic pneumothorax was transthoracic needle aspiration. ${ }^{3}$ followed by thoracentesis, subclavian venipuncture, and positive pressure ventilation. Hydro-pneumothorax, pyo-pneumothorax, hemopneumothorax results from collection of clear fluid, pus or blood respectively in the pleural cavity.

A bronchopleural fistula is a communication between the pleural space and the lung. The etiologies are varied. By far, the commonest cause for a bronchopleural fistula is pulmonary resection followed by necrotic lung infections. 
Chemotherapy or radiotherapy (For lung cancer) and tuberculosis are less commonly known causes for bronchopleural fistula as per literature. ${ }^{4,5}$

\section{MATERIAL AND METHODS}

This is a prospective study of 54 cases of spontaneous pneumothorax with bronchopleural fistula, which were admitted in Department of Pulmonary Medicine, SVRRGGH, Tirupathi, over a period of 1 year from July 2014 to July 2015.

\section{Inclusion Criteria}

All patients who presented with primary and secondary spontaneous pneumothorax, hydro- or pyo-pneumothorax having bronchopleural fistula during the study period were admitted and taken into the study. All patients with pneumothorax and bronchopleural fistula who were above 18 years and willing to participate in the study were included.

\section{Exclusion Criteria}

All pneumothorax patients who were less than 18 years, not willing to participate in the study and with traumatic and post-surgical pneumothorax were excluded.

\section{RESULTS}

In the study period, out of 120 pneumothorax patients 54 patients with bronchopleural fistula were diagnosed. In 34 of the 54 patients, that is in $63 \%$ the bronchopleural fistula healed spontaneously in 2 weeks' time. In 16 of the patients even after 15 days of intercostal tube drainage, the bronchopleural fistula did not heal and they had to be referred to the cardiothoracic surgeon for decortication/pleurectomy.

Forty six of the 54 patients $(85.2 \%)$ were males and 8 $(14.8 \%)$ were females; 45 patients $(83 \%)$ had TB pneumothorax, out of this 2 were MDR TB patients; 9 patients $(17 \%)$ had non-TB pneumothorax, in which 2 were carcinoma lung; 7 (13\%) out of 54 patients, all men had diabetes, 2 of the 54 were HIV positive. There were 4 deaths, all of them due to aspiration pneumonia.

\section{DISCUSSION}

Generally, secondary pneumothoraces occur in the setting of underlying pulmonary disease, which most often is COPD. But in our study, secondary spontaneous pneumothoraces are seen most commonly in individuals affected with TB.

The prevalence of secondary spontaneous pneumothorax in patients hospitalized with pulmonary tuberculosis is between $1 \%$ to $3 \%$ according to most studies. ${ }^{6}$
In one series from Spain, tuberculosis was the second leading cause of secondary spontaneous pneumothorax after COPD. ${ }^{7}$ Very surprisingly, in our study population of 54, nobody had COPD. As is expected, males far outnumbered the females, $85.2: 14.2 \% .^{8}$

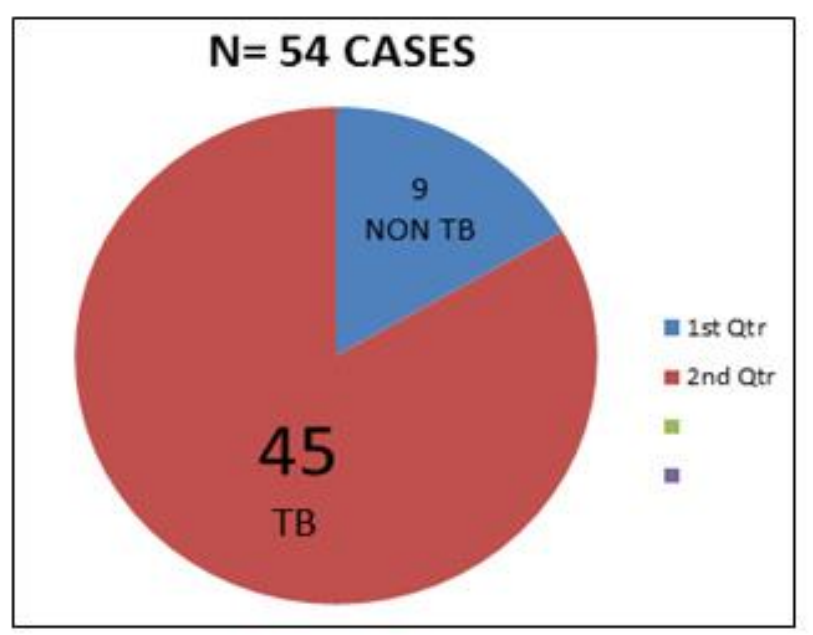

Fig.1: Etiology of Bronchopleural Fistula

In our study, 2 patients had HIV and 7 patients had diabetes; contrary to expectations their bronchopleural fistulae healed spontaneously with tube thoracostomy. ${ }^{9}$ and appropriate therapy. Diabetics and HIV patients being immunocompromised generally show poor healing of wounds, but our study seems to negate that.

The etiology of pneumothorax in the patient with AIDS may be changing. In a review of 9,831 non-treated HIVinfected patients, 105 of the patients had a spontaneous pneumothorax. The most common etiology was bacterial pneumonia (34.3\%) followed by P. jirovecii infection (29.5\%) and tuberculosis $(15.2 \%) .^{10}$ In our study, both patients with HIV had TB.

In our study, 2 females with lung metastasis (1 from osteogenic sarcoma and another one from carcinoma breast) had bronchopleural fistula. In both of them, the fistula did not close and before they could consult the cardiothoracic surgeon they died. These findings are in agreement with such previous studies.

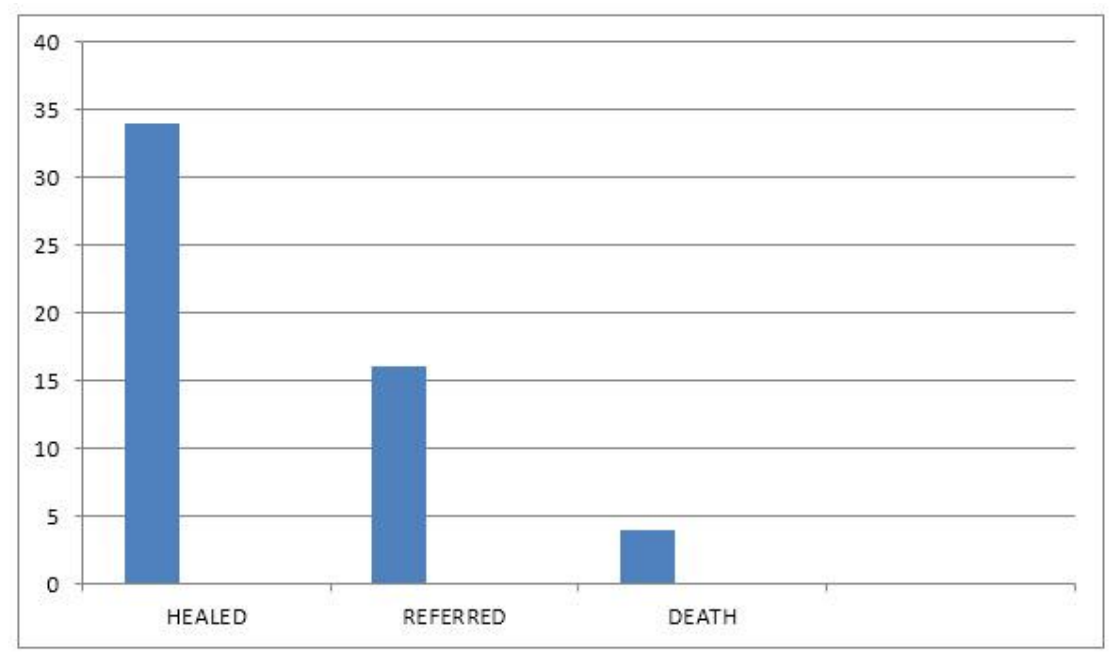

Fig. 2: Fate of Bronchopleural Fistula 
Bronchopleural Fistula (BPF) is a relatively rare, but feared complication of several pulmonary conditions. Bronchopleural fistula carries a high morbidity and mortality and is associated with prolonged hospital stay and high resource utilization. In approximately $20 \%$ of the patients with secondary spontaneous pneumothorax, the lung remains unexpanded or an air leak persists after 7 days..$^{11}$ In our study, in 16 of the patients (29.6\%), even after 15 days of intercostal tube drainage the bronchopleural fistula did not heal and they had to be referred for surgery. This is in congruence with previous such studies.

In our study there were 4 deaths, all of them due to aspiration pneumonia. Available literature says that aspiration pneumonia is the commonest cause of death in pneumothorax patients with bronchopleural fistula and this was also seen in our study.

\section{CONCLUSIONS}

According to our study, men with TB pneumothorax, hydroand pyo-pneumothorax seem to have delayed and nonclosure of the bronchopleural fistula. Carcinoma lung seems to be associated with non-closure of the bronchopleural fistula more frequently. Diabetes and HIV do not influence the closure of the bronchopleural fistula according to our study.

\section{REFERENCES}

1. Gobbel WG Jr., Rhea Wg Jr., Nelson IA, et al. Spontaneous Pneumothorax. J Thorac Cardiovasc Surg 1963;46:331-345.

2. Lesur O, Delorme N, Fromaget JM, et al. Computed tomography in the etiologic assessment of idiopathic spontaneous pneumothorax. Chest 1990;98:341-347.
3. Geraghty PR, Kee ST, McFarlane G, et al. CT-guided transthoracic needle aspiration biopsy of pulmonary nodules: needle size and pneumothorax rate. Radiology 2003;229:475-481.

4. Cerfolio RJ. The incidence, etiology and prevention of postresectional bronchopleural fistula. Semin Thorac Cardiovasc Surg 2001;13:3-7.

5. Hankins JR, Miller JE, Attar S, et al. Bronchopleural fistula: 13 year experience with 77 cases. J Thorac Cardiovasc Surg 1978;76:755-762.

6. Freixinet JL, Caminero JA, et al. spontaneous pneumothorax and tuberculosis. Long-term follow-up. Eur Respir J 2011;38:126-131.

7. Blanco-Perez J, Bordon J, Pineiro-Amigo L, et al. Pneumothorax in active pulmonary tuberculosis: resurgence of an old complication? Respir Med 1998;92:1269-1273.

8. Gupta D, Hansell A, Nichols T, et al. Epidemiology of pneumothorax in England. Thorax 2000;55:666-671.

9. Baumann MH, Strange C, Heffner JE, et al. Management of spontaneous pneumothorax: an ACCP Delphi Consensus Statement. Chest 2001;119:590-602.

10. Rivero A, Perez-Camacho I, LozanoF, et al. Andalusian group for the study of infectious diseases (GAEI). Etiology of spontaneous pneumothorax in 105 HIVinfected patients without highly active antiretroviral therapy. Eur J Radiol 2009;71:264-268.

11. Fraser RS, Muller NL, Colman N, et al. Diagnosis of Diseases of the Chest, Vol 4, 4th ed. Philadelphia, PA:WB Saunders 2000:2781-2794. 